\title{
The new method of modifying the hydrophobic properties of expanded perlite
}

\author{
Elżbieta Vogt ${ }^{1, *}$, Lukasz Płachta ${ }^{1}$ \\ ${ }^{1}$ University of Science and Technology, Energy and Fuel Department, Cracow, Poland
}

\begin{abstract}
The progressive industrialization and development of the automotive industry is the cause of the increasing demand for chemical products, especially oil products. Unfortunately, during processing, transportation or storage of these products, they get very often into the environment causing pollution. The removal of the results of accidents is still a current problem. The techniques which employ various types of sorbents deserve special attention among the several methods of eliminating the effects of pollutions. Moreover, expanded hydrophobic perlite is an interesting material among sorbents which are used on a large scale. The new method of modifying the hydrophobic properties of expanded perlite, with the use of solutions of stearic acid in organic solvents, was presented. The perlite that was used in research was produced by the PerliPol registered partnership in Bełchatów. Hydrophobic properties of the obtained materials were determined on the basis of the results achieved due to the modified film flotation method, "floating on water" test and on the basis of the value of water retention for individual samples. All grain fractions of perlite obtained hydrophobic properties which were better than or comparable to the hydrophobic properties of the HydroPerl (PerlPol) commercial material used to remove petroleum product pollution. The hydrophobization process significantly improved the adsorption capacity of modified perlite to petroleum product pollution.
\end{abstract}

\section{Introduction}

The progressive industrialization and development of the automotive industry is the cause of the increasing demand for chemical products, especially petroleum products. Unfortunately, during processing, transportation or storage of these products, they very frequently get into the environment causing pollution. KGPSP (The National Headquarters Of The State Fire Service) statistics (in Poland) report that the number of dangerous incidents involving petroleum hydrocarbons in 2001-2011 was between 2000 and 3000 per year [1]. The stable level of hazard preserved through the years results from the increase of safety conditions by using oil and petroleum products, probably associated with the use of modern technologies. However, accidents involving oil and its products spills, especially from tankers, transport tankers and industrial plants are still particularly dangerous for the environment [2-3]. Particularly worrying are the reports of environmental disasters in the

\footnotetext{
${ }^{*}$ Corresponding author: vogt@agh.edu.pl
} 
areas of large bodies of water such as: the Erika oil tanker disaster off the coast of France, the spill in November 1999 (30 thousand tons of diesel), the Prestige tanker disaster off the coast of Spain in 2002 (50 thousand tons), the explosion of the Deepwater Horizon oil rig in 2010 (about 666 thousand tons of oil) and other disasters [2-4].

The disaster recovery is still a current problem - it is costly and difficult. The techniques which employ various types of sorbents deserve special attention among the several methods of eliminating the consequences of pollution. Different types of sorbents are used: natural and processed ones. Among the natural sorbents we may mention the following: peat, sawdust, bark and wood, cellulose waste from the production of paper and cotton products, unprocessed crushed minerals, natural zeolites. Synthetic organic sorbents such as propylene or polyurethane and processed mineral sorbents such as expanded perlite or modified zeolites are examples of processed applied sorbents [5-6].

Among these sorbents expanded perlite is an interesting material which is used on a large scale. Perlite is an alumina-silicate rock of volcanic origin. This material is extracted mainly in Turkey, Greece, USA, Italy, Japan and Hungary. This rock can be subjected to a process of expansion by soaking it in a high temperature (approx. 650$\left.870^{\circ} \mathrm{C}\right)$ [7-9].

Many manufacturers producing sorbents on the basis of perlite are known. The main sellers on the Polish market are the following companies: PerliPol [10], Perlit-Polska [11], Zębiec [12] the Czech company PERLIT [13]. They offer raw expanded perlite and hydrophobized material. Hydrophobic perlite obtained by modification of the raw perlite has especially good sorption properties. Tests prove that hydrophobic properties significantly improve the absorption capacity of various kinds of sorbents used for the removal of pollutions, especially petroleum products. [10, 14-15] The technologies of perlite hydrophobic manufacturing that are known are based mainly on silicone compounds $[10,16]$.

\section{Materials and methods}

The perlite that was used in research, of varying grain size, was produced by the PerliPol registered partnership in Bełchatów [10]. According to the manufacturer data, the tested material has the following chemical composition: $\mathrm{SiO}_{2}(65-75 \%), \mathrm{Al}_{2} \mathrm{O}_{3}(10-18 \%), \mathrm{K}_{2} \mathrm{O}+$ $\mathrm{Na}_{2} \mathrm{O}(6-9 \%), \mathrm{MgO}+\mathrm{CaO}(2-6 \%), \mathrm{Fe}_{2} \mathrm{O}_{3}$ (1-5\%) [17]. Granulometric composition of grain fractions used in the research is provided in Table 1. Hydrophobized expanded HydroPerl perlite, the commercially available product of the PerliPol partnership, was used as a comparative material. HydroPerl is obtained by the hydrophobization of EP 150 raw perlite with the use of silicone compounds. The hydrophobization procedure is the manufacturer's secret [10]. The hydrophobic material, according to the manufacturer's data, is characterized by the following granulometric composition: $1,00-4,00 \mathrm{~mm}(20-70 \%)$, $<1,00 \mathrm{~mm}(30-80 \%),<0,315 \mathrm{~mm}(\max 40 \%)$. The HydroPerl absorption of petroleum products that was determined according to the manufacturer's method is less than $350 \mathrm{l} / \mathrm{m}^{3}$ [17].

Table 1. Perlite type [17].

\begin{tabular}{|l|c|c|c|}
\hline Perlite type & EP 180 & EP 150 & EP 100 \\
\hline Granulation $[\mathrm{mm}]$ & {$[\%]$} & {$[\%]$} & {$[\%]$} \\
\hline+1.00 & $\min 60$ & $\max 20$ & $\max 20$ \\
$+0,50$ & $0-100$ & $15-60$ & $10-80$ \\
$+0,025$ & $\max 10$ & $\min 60$ & $\min 60$ \\
\hline
\end{tabular}


Stearic acid as a modifier of hydrophobic properties of the raw perlite (EP 180, EP 150, EP 100) was used in research. The modification process was carried out with the use of solutions of stearic acid in organic solvents. Ethanol and petroleum ether stearic acid solutions were used. The concentration of the solution was selected in such a way that after evaporation of the solvent, the content of stearic acid in a solid material was $8 \%(\mathrm{w} / \mathrm{w})$. Hydrophobization was carried out by mixing stearic acid solution with the raw perlite in a laboratory evaporator, at an increased temperature. The detailed descriptions of the conducted hydrophobization processes may be found in the author's earlier works [18-19].

\subsection{Measurement methods}

Hydrophobic properties of the obtained materials were determined on the basis of the results obtained by the modified film flotation method - the "floating on water" test and on the basis of the value of water retention (absorption) for individual samples [19-22]. The study of petroleum adsorption was carried out on basis of the instructions available on the website of the manufacturer, PerliPol $[10,17]$

\subsubsection{Evaluation of the hydrophobization degree by the "floating on water" test}

In this work a relative evaluation of the hydrophobization degree of the analysed materials was based on a simple experiment, the so-called "floating on water" test [19-21]. The experiment consisted in the placing of a small amount of material on the surface of water in a beaker. The hydrophobization degree of the materials that were modified in the work was evaluated on the basis of the material amount floating on the liquid surface for a specified period of time. Fig. 1 presents the example photographs of the "floating on water" test for the EP 100 perlite. The photographs were obtained immediately after placing the samples on the water surface. perlite.

Fig. 2 presents the example photographs of the "floating on water" test for the EP 150
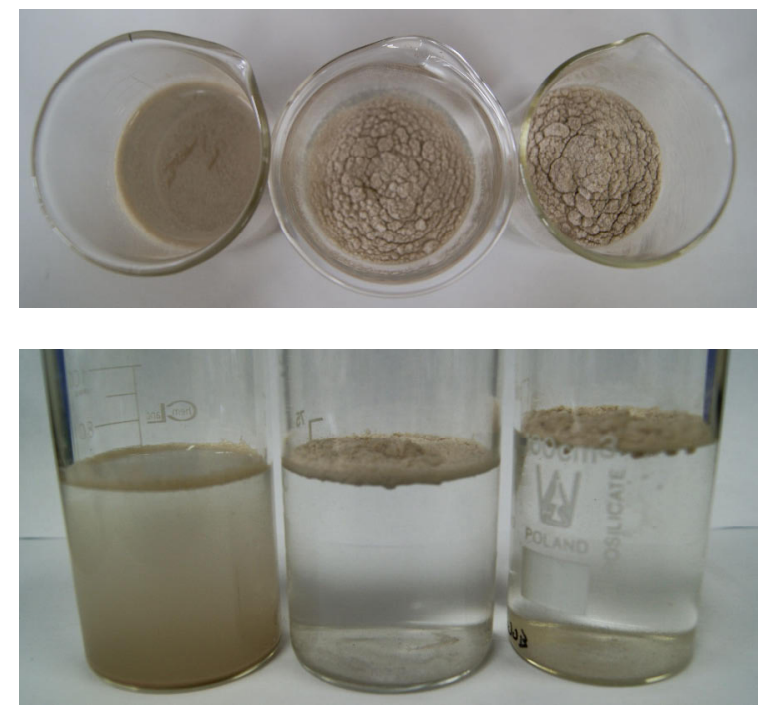

Fig. 1. Photographs of the "floating on water" test for the EP 100 perlite. From the left: raw material, samples modified by: ethanol stearic acid solution, petroleum ether stearic acid solution. 

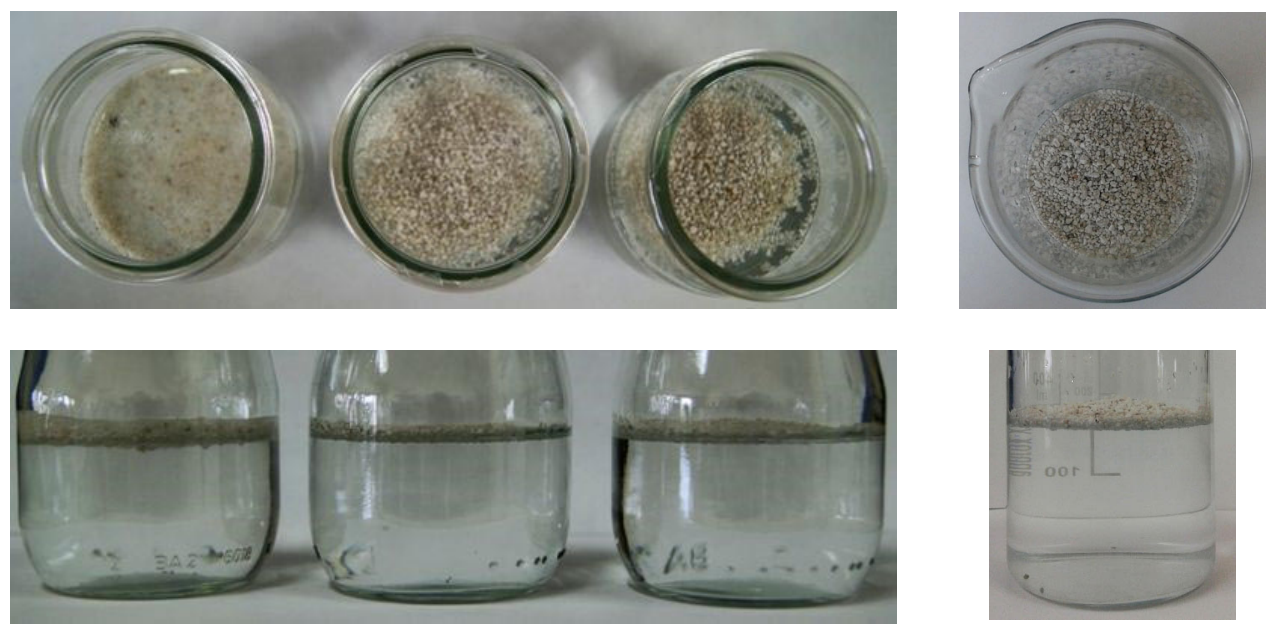

Fig. 2. Photographs of the "floating on water" test for the EP 150 perlite. From the left: raw material, samples modified by: ethanol stearic acid solution, petroleum ether stearic acid solution, HydroPerl.

\subsubsection{Evaluation of the water absorption}

Water absorption was determined with the use of a modified method based on the [22] standard. The test portion of material was placed in the beaker and completely immersed in the water. After that the test portion was placed in a wire basket. The sample remained in the basket for a certain amount of time until the water has stopped dripping. In our test absorbent clothes have not been used for draining excess water. The amount of water determined during a test which was conducted in such a way is adequate to the amount of water retained in the layer of perlite, during the removal of pollutions.

The mass $\mathrm{m}_{1}$ of the saturated test portion of material was obtained. The water absorption (WA) was calculated from the formula 1 :

$$
W A=\frac{m_{1}-m_{2}}{m_{2}}
$$

Where: $\mathrm{m}_{1}-$ mass of the saturated test portion $[\mathrm{g}] \mathrm{m}_{2}-$ mass of the oven-dried at $105^{\circ} \mathrm{C}$, test portion $[\mathrm{g}]$.

The obtained results are presented in Table 2.

Table 2. Water absorption.

\begin{tabular}{|l|c|c|c|c|}
\hline Perlite type & EP 180 & EP 150 & EP 100 & HydroPerl \\
\hline \multirow{4}{*}{$\begin{array}{l}\text { WA } \\
{\left[\mathrm{g}_{\text {water }} / \mathrm{g}_{\text {perlite }}\right]}\end{array}$} & \multicolumn{3}{|c|}{ Raw material } \\
\cline { 2 - 4 } & 4.9 & 9.3 & \multirow{3}{*}{4} \\
\cline { 2 - 4 } & \multicolumn{3}{|c|}{ Samples modified by ethanol solution } \\
\cline { 2 - 4 } & 4.6 & 6.5 & 3.9 \\
\cline { 2 - 4 } & \multicolumn{2}{|c|}{ Samples modified by petroleum ether solution } & \\
\cline { 2 - 4 } & 5.0 & 7.4 & 2.6 & \\
\hline
\end{tabular}




\subsubsection{Evaluation of the petroleum products absorption}

The study of petroleum adsorption was carried out on basis of the instructions available on the website of the manufacturer, PerliPol $[10,17]$. The petroleum products absorption (Ads) was calculated from the formula 2 :

$$
A d s=\frac{15-V_{\text {petroleum }}}{25} \cdot 1000
$$

Where: Ads - petroleum products adsorption $\left[1 / \mathrm{m}^{3}\right] \mathrm{V}_{\text {petroleum }}$ - volume of non-absorbed petroleum $\left[\mathrm{cm}^{3}\right]$.

The obtained results are presented in Table 3.

Table 3. Petroleum absorption.

\begin{tabular}{|l|c|c|c|c|}
\hline Perlite type & EP 180 & EP 150 & EP 100 & HydroPerl \\
\hline \multirow{4}{*}{$\begin{array}{l}\text { Ads } \\
{\left[1 / \mathrm{m}^{3}\right]}\end{array}$} & 160 & 220 & 80 & \multirow{3}{*}{30} \\
\cline { 2 - 4 } & \multicolumn{3}{|c|}{ Raw material } \\
\cline { 2 - 4 } & 280 & 420 & 480 \\
\cline { 2 - 4 } & \multicolumn{3}{|c|}{ Samples modified by ethanol solution } & \\
\cline { 2 - 4 } & \multicolumn{2}{|c|}{ Samples modified by petroleum ether solution } & 520 & \\
\cline { 2 - 4 } & 200 & 400 & & \\
\hline
\end{tabular}

\section{Discussion and conclusions}

It is noticed that the different fractions of the raw perlite have different initial hydrophobic properties. In the photographs (Figures 1 and 2) we may see that the whole portion of the EP 100 raw perlite falls to the bottom of the beaker. The EP 150 raw material wetted up but still floats on the water surface. The sample EP 180 raw perlite also floated on the surface of the water.

Hydrophobic properties of all materials after the modification process have improved significantly. All modified pearlite grain fractions, as well as the HydroPerk commercial product did not wet up and they float on the water surface. This can be seen in the photographs (Figs. 1, 2). All materials were left on the surface for a period of 24 hours. At this time, no change was observed in the degree of wetted up perlite.

Water absorption values (WA) listed in Table 2 confirm good hydrophobic properties of perlite after modification. Moreover, it can be seen that the amount of absorbed water depends on the composition of the grain fraction perlite. In the case of EP 180 fractions it may be assumed that the material after the modification absorbs a comparable amount of water as a raw material. Water impregnability of the EP 100 and EP 150 materials after the hydrophobization process significantly decreased. Particularly good results are obtained for the hydrophobic EP 100 material, because the obtained water absorption value is lower than in the case of the HydroPerl commercial material.

The values of petroleum product adsorption (Ads) listed in Table 2 are higher for the hydrophobized EP 150 and EP 100 material than for HydroPerl commercial material, and this is what demonstrates good sorption properties of the modified perlite. Only hydrophobized EP 180 material is characterized by lower petroleum product absorption value. The study that was conducted confirms the information from the literature that 
hydrophobic properties significantly improve the absorption capacity of sorbents used for the removal petroleum products $[9-10,14]$.

In conclusion, the raw materials (expanded perlite) are characterized by natural hydrophobic properties but upon contact with water raw expanded perlite gets wet. Better hydrophobic properties are required from the expanded perlite which is used to remove petroleum pollutions. Methods of the hydrophobization of perlite with the use of silicon compounds are known $[10-13,15]$. The presented study demonstrated that one may change the hydrophobic properties of the expanded perlite with the use of stearic acid solutions in organic solvents. Almost all of the grain fractions of perlite modified during the work obtained hydrophobic properties comparable to those of hydrophobic properties of the HydroPerl commercial product (PerlPol). The hydrophobization process that is described significantly improved adsorption capacity of modified perlite to petroleum product pollutions.

Acknowledgements. The author is grateful to the AGH University of Science and Technology (Project 11.11.210.244) for financial support.

\section{References}

1. J. Rakowska, K. Radwan, Z. Ślosorz, E. Pietraszek, M. Łudzik, P. Suchorab, Scientific and Research Centre for Fire Protection, J. Tuliszkowski, National Research Institute Józefów (2012)

2. A. Jernelöv, Ambio, 39, 5-6 (2010)

3. M. Blackburn, C.A.S. Mazzacano, C. Fallon, S.H. Black, Oil in our OSEANS. A Review of the Impacts of Oil Spills on Marine Invertebrates, Portland, OR: The Xerces Society for Invertebrate Conservation (2014)

4. M. M. Auffret, S. Duchemin, I. Rousseau, A. BoutetTanguy, D. Moraga, A. Marhic. Aquat. Living Resour. 1, 3 (2004)

5. L. Bandura, M. Franus, G. Józefaciuk, W. Franus, Fuel 147 (2015)

6. S. Suni, A.L. Kosunen, M. Hautala, A. Pasila, M. Romantschuk, Mar. Pollut. Bull. 49 (2004)

7. M. Arifuzzaman, H. Sung Kim, Constr. Build. Mater. 93 (2015)

8. A. Rózycka, W. Pichór, Constr. Build. Mater. 120 (2016)

9. M. Gursoy, M. Karaman, Chem. Eng. J. 284 (2016)

10. PerliPol, http://www.perlipol.com.pl/pl [July 2016]

11. Perlit-Polska, http://www.perlit-polska.pl [July 2016]

12. Zębiec, http://www.zebiec.pl [July 2016]

13. PERLIT, http://www.perlit.cz [July 2016]

14. Smart Green Technology, http://www.smart-green.eu/download/2012-0831\%20Inf0ormacja\%20o\%20produktach.pdf [July 2016]

15. M, Giroux, E. Sahadeo, R. Libera, A. Maurizi, I. Giles, A. Marteel-Parrish, Polyhedron 114 (2016)

16. M. E. Wilson, Hydrophobic expanded perlite compositions and process for preparing the same, United States Patent, 4,889,747 (89)

17. http://www.perlipol.com.pl/dokumenty/karta_techniczna_perlitu_ekspandowanego_20 10.pdf [July 2016]

18. E. Vogt, PJCT 10, 1, (2008)

19. E. Vogt, Cem. Lime Concrete 3 (2012)

20. D.W. Fuerstenau, M.C. Williams, Colloid. Surface. 22 (1987)

21. E. Vogt, I. Opaliński, ICheaP-9 Conference, Chem. Eng. Trans. 17, (Editor Sauro Pierucci, Rome 2009)

22. EN 1097-6:2013 standard, Tests for mechanical and physical properties of aggregate 